\title{
IRES-dependent translation of egr2 is induced under inflammatory conditions
}

\author{
DANIELA RÜBSAMEN, ${ }^{1}$ JOHANNA S. BLEES, ${ }^{1}$ KATHRIN SCHULZ, ${ }^{1}$ CLAUDIA DÖRING, ${ }^{2}$ \\ MARTIN-LEO HANSMANN, ${ }^{2}$ HEINRICH HEIDE, ${ }^{3}$ ANDREAS WEIGERT, ${ }^{1}$ TOBIAS SCHMID, ${ }^{1,4,5}$ \\ and BERNHARD BRÜNE ${ }^{1,4}$ \\ ${ }^{1}$ Institute of Biochemistry I, Goethe-University Frankfurt, 60590 Frankfurt, Germany \\ ${ }^{2}$ Senckenberg Institute of Pathology, Goethe-University Frankfurt, 60590 Frankfurt, Germany \\ ${ }^{3}$ Molecular Bioenergetics Group, Faculty of Medicine, Goethe-University Frankfurt, 60590 Frankfurt, Germany
}

\begin{abstract}
Adjusting translation is crucial for cells to rapidly adapt to changing conditions. While pro-proliferative signaling via the PI3KmTOR-pathway is known to induce cap-dependent translation, stress conditions, such as nutrient deprivation or hypoxia often activate alternative modes of translation, e.g., via internal ribosome entry sites (IRESs). As the effects of inflammatory conditions on translation are only poorly characterized, we aimed at identifying translationally deregulated targets in inflammatory settings. For this purpose, we cocultured breast tumor cells with conditioned medium of activated monocyte-derived macrophages (CM). Polysome profiling and microarray analysis identified early growth response-2 (egr2) to be regulated at the level of translation. Using bicistronic reporter assays, we found that egr 2 contains an IRES within its $5^{\prime}$ UTR, which facilitated enhanced translation upon CM treatment. We further provide evidence that the activity of egr2-IRES was induced by IL-1ß and p38-MAPK signaling. In addition, we identified several potential IRES trans-acting factors (ITAFs) such as polypyrimidine tract binding protein (PTB) and hnRNP-A1 that directly bind to the egr2-5'UTR. In summary, our data provide evidence that egr2 expression is translationally regulated via an IRES element, which is responsive to an inflammatory environment.
\end{abstract}

Keywords: egr2; translation; IRES; inflammation; IL-1ß; p38-MAPK

\section{INTRODUCTION}

Regulation of translation primarily takes place at the level of translation initiation. This process involves the assembly of the translation initiation complex at the $5^{\prime}$ untranslated region ( 5 ' UTR) of the mRNA to recruit the ribosomes (Sonenberg and Hinnebusch 2009; Silvera et al. 2010). Formation of the initiation complex, comprising eukaryotic initiation factors (eIFs) such as the RNA helicase eIF4A, the scaffolding protein eIF4G, and the cap-binding protein eIF4E, is highly regulated by the PI3K-mTOR pathway (Guertin and Sabatini 2007). Specifically, mTOR phosphorylates and thereby activates $\mathrm{p} 70^{\mathrm{S} 6 \mathrm{~K}}$, which in turn phosphorylates the $40 \mathrm{~S}$ ribosomal subunit, a critical step in translation initiation. Moreover, mTOR inhibits the $4 \mathrm{E}$-binding protein (4E-BP), which, in a hypophosphorylated state, sequesters

\footnotetext{
${ }^{4}$ These authors share senior authorship.

${ }^{5}$ Corresponding author

E-mail T.Schmid@biochem.uni-frankfurt.de

Article published online ahead of print. Article and publication date are at http://www.rnajournal.org/cgi/doi/10.1261/rna.033019.112.
}

and, thus, inhibits the cap-binding protein eIF4E. Hyperphosphorylation of $4 \mathrm{E}-\mathrm{BP}$ by mTOR releases eIF4E, which then interacts with the cap-structure of mRNAs to recruit other eIFs as well as the ribosomal subunits (Pause et al. 1994).

Enhanced activation of PI3K-mTOR signaling has been shown to specifically stimulate the translation of various tumor-associated factors with highly structured 5' UTRs such as cyclin D1 (Averous et al. 2008). Thus, deregulated translation is increasingly being used as a target for the development of novel tumor therapeutics. So far translationoriented therapies predominantly target the kinase mTOR (e.g., rapamycin and its analogs) (Faivre et al. 2006). Yet, under conditions where cap-dependent translation is inhibited, the protein synthesis of various survival genes is maintained in a cap-independent manner, e.g., via internal ribosome entry sites (IRESs) (Holcik 2004). IRES elements facilitate initiation of translation independently of the capbinding protein eIF4E. Such elements were described for various oncogenes like Hif- $1 \alpha$ (Lang et al. 2002) and Bcl-2 (Sherrill et al. 2004). In most cases, activation of IRES elements is mediated via IRES trans-acting factors (ITAFs), 
such as the polypyrimidine tract binding protein (PTB), which bind to short sequences or secondary structures of the $5^{\prime}$ UTR (Spriggs et al. 2005). Binding of these proteins initiates conformational changes of the 5' UTR structure, thereby allowing the interaction of eIFs and ribosomal subunits with the mRNA to facilitate translation.

While translation initiation is modulated by a variety of stimuli including mitogens (Sonenberg and Hinnebusch 2007), hormones (Proud 2006), nutrients (Proud 2004), and stress signals (Wek et al. 2006), little is known about the effect of inflammation on translational regulation. Therefore, the present study aimed at identifying translationally deregulated targets during inflammation-associated tumorigenesis. Using polysome profiling and microarray analysis of breast tumor cells treated with supernatants of activated macrophages, we identified genes that were regulated predominantly at the level of translation in the tumor cells. Among these, early growth response-2 (egr2) was identified as a novel translationally regulated target. Translation of egr2 was induced by IL-1 $\beta$ and subsequent p38-mitogenactivated protein kinase (MAPK) activation. In addition, we identified an IRES element within the 5' UTR of egr2 and found several potential ITAFs such as PTB and hnRNP-A1 to bind to the 5' UTR of egr2. Thus, we propose that egr2 translation is regulated in an IRES-dependent manner by IL-1 $\beta$ and $\mathrm{p} 38$-MAPK.

\section{RESULTS}

\section{Inflammatory conditions provokes translational changes of specific mRNAs}

In order to identify proteins that are translationally regulated under inflammatory conditions, we established an in vitro model for macrophage-associated inflammation. Briefly, we used supernatants of activated U937 monocytederived macrophages (CM) which we have previously shown to contain significantly elevated protein levels of the proinflammatory mediators TNF $\alpha$, IL-6, and IL- 8 as compared to supernatants of undifferentiated U937 monocytes (Ctr) (Schmid et al. 2011). Additionally, CM enhanced AP1-transactivation and degradation of the tumor suppressor Pdcd4 (Yasuda et al. 2010), thereby providing evidence for the induction of a protumorigenic program in MCF7 cells.

To search for proteins that are regulated at the translational level, MCF7 cells were treated for $4 \mathrm{~h}$ with CM or Ctr, followed by polysomal fractionation. To this end, cytoplasmic lysates were generated and layered on a sucrose gradient leading to sedimentation of mRNAs according to their ribosome occupancy after ultracentrifugation (Fig. 1). Notably, the polysome profile of MCF7 cells treated with $\mathrm{CM}$ did not show obvious differences compared to Ctr (Supplemental Fig. S1A,B). The ribosome distribution was confirmed in single fractions using a denaturing agarose

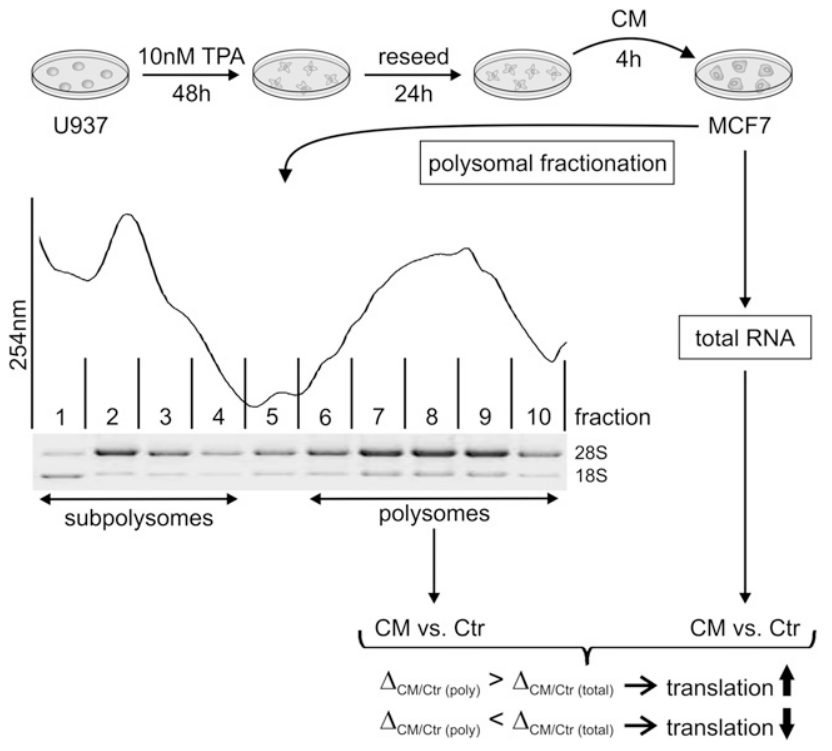

FIGURE 1. Experimental setup. U937 cells were differentiated with $10 \mathrm{nM}$ TPA for $48 \mathrm{~h}$ or left untreated. Then, cells were trypsinized, washed with PBS, and reseeded in fresh medium. After $24 \mathrm{~h}$, the conditioned medium from activated U937 monocyte-derived macrophages (CM) or undifferentiated U937 monocytes (Ctr) was harvested. MCF7 cells were incubated for $4 \mathrm{~h}$ with CM or Ctr. Subsequently, the respective cellular lysates were subjected to polysomal fractionation. Equal aliquots of RNA isolated from single fractions were analyzed using denaturing agarose gel electrophoresis to verify $28 \mathrm{~S}$ and $18 \mathrm{~S}$ rRNA distribution as indicators for ribosome distribution. Pooled polysomal fractions 6-10 and total RNA were analyzed using whole genome microarrays. Comparing polysomal changes (CM vs. Ctr) with total changes (CM vs. Ctr) revealed translationally regulated genes.

gel to visualize $28 \mathrm{~S}$ and $18 \mathrm{~S}$ rRNA (Fig. 1). For global analysis of translationally regulated mRNAs, polysomal fractions 6-10 were pooled and subjected to microarray analysis. In parallel, microarray analysis of total mRNA was performed. mRNAs that significantly changed in the polysome-associated portion but not on the total level were considered as translationally regulated. Among the mRNAs identified to shift into or out of the polysomal fractions, egr2, plaur, map3k5, gfra2, and cblb showed the strongest translational induction (2.5- to 7.0-fold), whereas apq11, fgd3, rnf214, fance, and lrrc20 displayed the strongest translational repression $(-2.2-$ to -2.7 -fold) (Table 1$)$.

\section{Egr2 is translationally up-regulated under inflammatory conditions}

As early growth response-2 showed the highest increase in polysomal RNA of all targets (7.0-fold), we chose this target for further investigation. To this end, we analyzed the relative amount of egr 2 mRNA in single fractions after Ctr or CM treatment and found that egr2 mRNA distribution decreased in the monosomal and increased in the polysomal fraction in response to CM (Fig. 2A). In contrast, the mRNA distribution of gapdh was not affected by CM (Fig. 2B). To 
TABLE 1. List of highest translationally up- and down-regulated genes

\begin{tabular}{lccc}
\hline Symbol & Poly change & $P$-value & Acc. no. \\
\hline egr2 & 7.0 & $1.99 \times 10^{-04}$ & NM_000399.2 \\
plaur & 3.9 & $7.03 \times 10^{-04}$ & NM_002659.2 \\
map3k5 & 2.9 & $4.24 \times 10^{-04}$ & NM_005923.3 \\
gfra2 & 2.6 & $2.29 \times 10^{-03}$ & NM_001495.4 \\
cblb & 2.5 & $1.77 \times 10^{-03}$ & NM_170662.3 \\
aqp11 & -2.7 & $1.17 \times 10^{-02}$ & NM_173039.1 \\
fgd3 & -2.5 & $2.16 \times 10^{-02}$ & NM_033086.2 \\
rnf214 & -2.4 & $3.58 \times 10^{-03}$ & NM_207343.2 \\
fance & -2.2 & $7.41 \times 10^{-03}$ & NM_021922.2 \\
Irrc20 & -2.2 & $2.70 \times 10^{-03}$ & NM_018239.2 \\
\hline
\end{tabular}

allow for statistical evaluation of the observed changes, mRNA distribution in response to CM was normalized to the Ctr distribution for individual experiments. As predicted based on the individual experiments, egr2 mRNA distribution significantly decreased in monosomal fractions $1-3$, while it significantly increased in polysomal fractions $6-10$ (Fig. 2C). Again, no difference was observed for gapdh (Fig. 2D). For control purposes, we determined changes in the mRNA distribution of the related egr3, which was not identified to be translationally regulated in the microarray analysis. As expected, no significant changes could be observed for the egr3 mRNA distribution in response to $\mathrm{CM}$ (Fig. 2E). To get a measure for overall CM-induced translational changes, the mRNA abundance in pooled polysomal fractions $6-10$ was determined relative to $\mathrm{Ctr}$ and yielded a significant increase of $1.96 \pm 0.13$ for egr2, whereas egr3 remained unaltered (Fig. 2F).

These data indicate that egr 2 translation is specifically induced under inflammatory conditions.

\section{IL-1 $\beta$ induces translational up-regulation of egr2}

To elucidate molecular mechanisms and pathways enhancing translation of egr2, we initially analyzed changes of mRNA expression under these conditions. One hundred fifty-seven genes were found to change more than twofold on total mRNA level. These targets were subjected to pathway analysis using Ingenuity software. Within the associated network functions, inflammatory and cancer responses were enriched. Similarly, molecular functions were indicative of tumorigenic changes (cell growth, proliferation, and cellular movement) (Table 2). These results further support the concept that TPAactivated U937 monocyte-derived macrophages induce a protumorigenic and inflammatory response in MCF7 cells. We also found that these macrophages secrete physiological amounts of IL-1 $\beta(91.7 \pm 18.2 \mathrm{pg} / \mathrm{mL})$, whereas no IL- $1 \beta$ was secreted by undifferentiated U937 monocytes (Fig. 3A). We next asked whether IL- $1 \beta$ might affect egr 2 translation in our system. To this end, we depleted IL- $1 \beta$ in CM by preincubating CM with IL-1 $\beta$ neutralizing antibody for $1 \mathrm{~h}$. As compared to the IgG control-treated CM, egr2 mRNA in the pooled polysomal fractions $6-10$ was significantly reduced to $0.86 \pm 0.03$ in response to IL-1 $\beta$-depleted CM (Fig. 3B). To determine if IL-1 $\beta$ alone is able to induce egr2 translation, we treated MCF7 cells with recombinant IL-1 $\beta$ $(50 \mathrm{ng} / \mathrm{mL})$ for $4 \mathrm{~h}$ and observed a significantly increased amount of egr 2 mRNA in the pooled polysomal fractions (1.64 \pm 0.11 relative to the control) (Fig. 3C).

Taken together, these data indicate that IL- $1 \beta$ suffices to induce egr 2 translation. Moreover, IL-1 $\beta$ appears to contribute to the induction of egr 2 translation in response to conditioned medium from activated monocyte-derived macrophages.
A

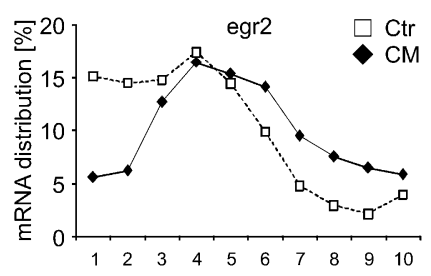

C

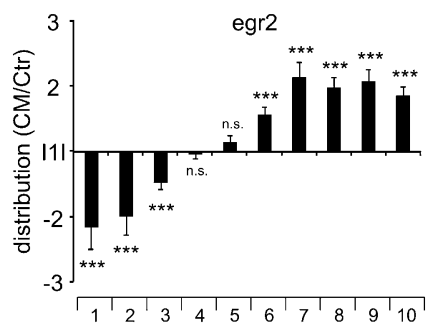

E

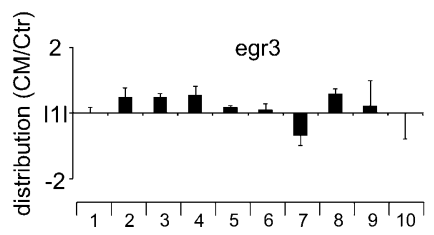

B

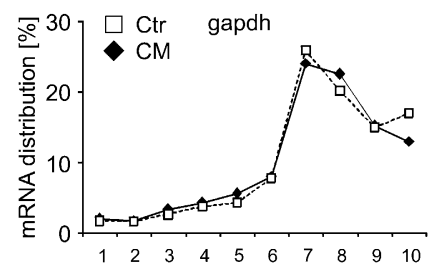

D

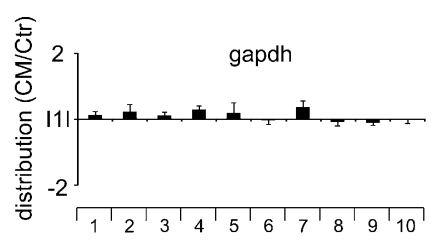

$\mathbf{F}$

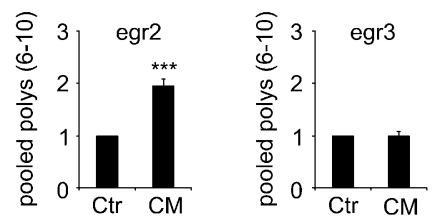

FIGURE 2. Egr2 is translationally up-regulated. MCF7 cells were treated with CM (black diamonds, solid line) or Ctr (white squares, dashed line) for $4 \mathrm{~h}$ and subjected to polysomal fractionation. RNA was isolated from single fractions and analyzed using RT-qPCR. The relative mRNA distribution of egr2 $(A)$ and gapdh $(B)$ is shown. Graphs are representative for at least three independent experiments. The ratio of mRNA distribution of CM to Ctr was calculated to visualize stimulus-dependent changes in single fractions for egr2 $(C)$, gapdh $(D)$, and egr3 $(E)$. (F) Pooled polysomal changes (fractions 6-10) of egr2 (left panel) and egr3 (right panel) in response to CM were determined relative to Ctr and normalized to gapdh. Data are presented as means \pm SEM $(n>3) .\left(^{* * *}\right) P<0.001$. 
TABLE 2. IPA of total changes

Associated network functions

Molecules

1. Cell death, proliferation, inflammatory response

2. Inflammatory response and disease

39

3. Cancer, cell cycle

Molecular and cellular functions

1. Cell death

2. Cellular growth and proliferation

3. Cellular movement

\section{IL-1 $\beta$-induced translational activation of egr2 is p38-MAPK-dependent}

We next aimed at understanding the signaling cascades linking egr 2 translation and IL- $1 \beta$. IL- $1 \beta$ is known to induce p38-MAPK activity via phosphorylation (Ichijo 1999). Accordingly, we found that p38-MAPK is rapidly and transiently phosphorylated in MCF7 cells in response to IL-1 $\beta$ treatment (Fig. $4 \mathrm{~A}$ ). Interestingly, a similar time course of p38-MAPK-phosphorylation was observed upon treatment with CM, whereas Ctr did not affect phosphorylation, i.e., activation of p38-MAPK (Fig. 4B). We then examined whether this pathway is involved in enhanced translation of egr2 under these conditions. Therefore, we cotreated MCF7 cells with CM in combination with the p38-MAPK inhibitor SB203580 $(10 \mu \mathrm{M})$. Inhibition of p38-MAPK did not affect global translation (Supplemental Fig. S1) but specifically decreased egr2 mRNA in the pooled polysomal fractions $6-10$ to $0.84 \pm 0.01$ relative to CM-treated cells (Fig. 4C; Supplemental Fig. S2). To verify that IL-1 $\beta$ contributed to the activation of p38-MAPK in response to $\mathrm{CM}$, we employed CM depleted for IL-1 $\beta$ by a neutralizing antibody approach. Indeed, neutralizing IL$1 \beta$ attenuated CM-induced phosphorylation of $\mathrm{p} 38$ MAPK (Fig. 4D).

In summary, these results indicate that IL-1 $\beta$ increases egr2 translation in a p38-MAPK-dependent manner.

\section{Various ITAFs bind to the 5' UTR of egr2}

As translation of individual mRNAs is often regulated via their 5' UTR (Pickering and Willis 2005), we next analyzed the $5^{\prime}$ UTR of egr2. The 5' UTR of egr2 proved to be relatively long, being composed of 326 bases (Fig. 5A). To determine potential structures in silico, we used mfold (Zuker 2003), which predicted a secondary structure containing various loops with a minimal free energy of $-89.40 \mathrm{kcal} / \mathrm{mol}$ (Fig. 5B). As complex secondary structures commonly require RNA-binding proteins for efficient translation, we performed streptavidin-tethered RNA-affinity purification with the $5^{\prime}$ UTR of egr2. For this purpose, we transcribed the $5^{\prime}$ UTR of egr2 and conjugated a biotin-label at the 5' end. The labeled transcript was then incubated with streptavidin agarose beads and protein lysate of 4-h CM-treated MCF7 cells. After elution and electrophoretic separation, proteins bound to the $5^{\prime}$ UTR of egr 2 were analyzed by mass spectrometry. A number of heterogeneous ribonucleoproteins (hnRNPs) and eukaryotic initiation factors were identified to bind to the 5' UTR of egr2, which did not precipitate in the control reaction using non-biotinylated RNA (Fig. 5C). Among the egr2-5'UTR binding proteins, we found PTB, hnRNP-A1, and human antigen R (HuR), all of which were previously shown to act as ITAFs associated with enhanced translation of target mRNAs (Vagner et al. 2001; Bonnal et al. 2005; Cobbold et al. 2010). To ensure an RNA-specific binding of these proteins to the egr2-5'UTR, the interaction was further verified via RNA-affinity purification, followed by Western analysis, including a control RNA of similar length (300 nt) encoding a fraction of

A

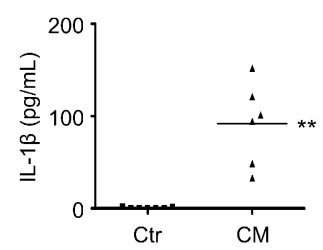

B

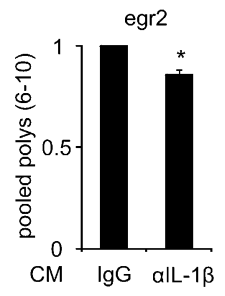

C

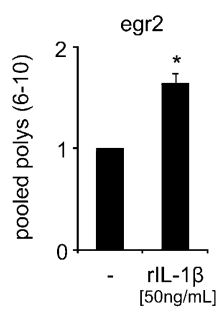

FIGURE 3. IL-1 $\beta$ induces translational up-regulation of egr2. (A) Secretion of IL-1 $\beta$ in Ctr and CM was analyzed using CBA assays $(n>3)$. $\left.\left(^{* *}\right) P<0.01\right)$. (B) CM was pretreated with $\mathrm{IgG}$ control $(5 \mu \mathrm{g} / \mathrm{mL})$ or neutralizing IL- $1 \beta$ antibody $(5 \mu \mathrm{g} / \mathrm{mL})$ for $1 \mathrm{~h}$ at $37^{\circ} \mathrm{C}$. Then, MCF7 cells were incubated with the respective $\mathrm{CMs}$ for $4 \mathrm{~h}$, followed by polysomal fractionation as described before. Changes of egr 2 mRNA in pooled polysomal fractions $6-10$ in response to $\mathrm{CM}+\alpha \mathrm{IL}-1 \beta$ relative to $\mathrm{CM}+\mathrm{IgG}$ were determined. (C) MCF7 cells were treated with human recombinant IL-1 $\beta$ $(50 \mathrm{ng} / \mathrm{mL}$ ) for $4 \mathrm{~h}$, followed by polysomal fractionation as described before. IL- $1 \beta$-induced changes for egr 2 mRNA in pooled polysomal distribution relative to control were analyzed using RTqPCR. Data are normalized to gapdh and presented as means \pm SEM $(n \geq 3) .\left(^{*}\right) P<0.05$. 
A

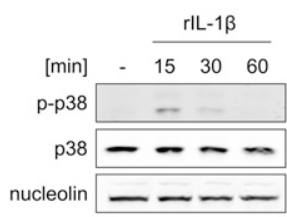

C

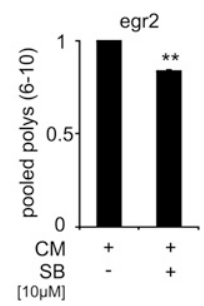

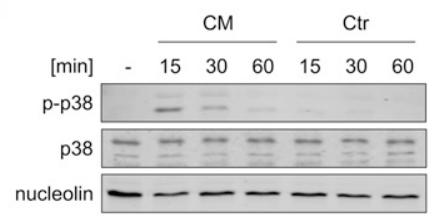

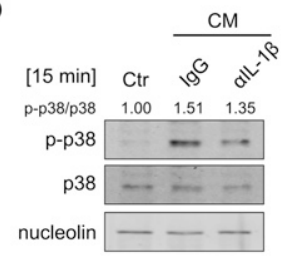

FIGURE 4. CM induces egr2 translation in a p38-MAPK-dependent manner. (A) MCF7 cells were treated with human recombinant IL-1 $\beta$ $(50 \mathrm{ng} / \mathrm{mL})$ to the indicated time points. Whole-cell extracts were subjected to Western analysis and probed with the indicated antibodies. Blots are representative for at least three independent experiments. (B) MCF7 cells were treated with CM or Ctr to the indicated time points. Whole-cell extracts were subjected to Western analysis and probed with the indicated antibodies. Blots are representative for at least three independent experiments. (C) MCF7 cells were treated for $4 \mathrm{~h}$ with CM alone or in combination with SB203580 $(10 \mu \mathrm{M})$, followed by polysomal fractionation. Change of egr2 mRNA in pooled polysomal fractions 6-10 in response to $\mathrm{CM}+\mathrm{SB}$ is given relative to CM. Data are normalized to gapdh and presented as means $\pm \operatorname{SEM}(n \geq 3)$. $\left.{ }^{* *}\right) P<0.01$. (D) MCF7 cells were treated for $15 \mathrm{~min}$ with Ctr and CM pretreated with $\operatorname{IgG}(5 \mu \mathrm{g} / \mathrm{mL})$ or IL-1 $\beta$ neutralizing antibody $(5 \mu \mathrm{g} / \mathrm{mL})$ as described before. Whole-cell extracts were subjected to Western analysis and probed with the indicated antibodies, followed by densitometric analysis. Levels of phospho-p38 were normalized to total p38 and are presented relative to Ctr. Blots are representative for at least three independent experiments.

human gapdh in reverse orientation (hrg). While PTB, hnRNP-A1, and HuR bound to egr2-5'UTR, no relevant binding to the control was observed (Fig. 5D). The minimal pulldown of HuR detected with the control appeared negligible compared to the amount of HuR pulled down with the egr2-5'UTR. Thus, our data support a specific binding of these three potential ITAFs to the egr2-5'UTR. However, we could not observe a differential binding when comparing CM- and Ctr-treated MCF7 lysates (data not shown).

Since binding of potential ITAFs indicates that an IRES element could be located in the $5^{\prime}$ UTR of egr2, we next tested whether inhibition of cap-dependent translation, in general, has an impact on egr2 translation. For this purpose, we treated MCF7 cells with the mTOR inhibitor rapamycin to inhibit cap-dependent translation and followed the polysomal distribution changes of mRNA in single fractions. As expected, gapdh mRNA abundance increased in monosomal fractions and decreased in polysomal fractions, indicative of an mRNA being translated cap-dependently

(Fig. 5E). Interestingly, egr2 translation appeared to be enhanced under these conditions, supporting cap-independent translation of egr2.

Taken together, the long, structured 5' UTR, the binding of potential ITAFs, and enhanced translation under conditions of inhibited cap-dependent translation were taken as indicators that egr2 mRNA is translated in an IRESdependent manner.

\section{Egr2-5'UTR contains an IRES element}

To determine the presence of IRES elements within the $5^{\prime}$ UTR of egr2, we used a bicistronic reporter plasmid. This construct expresses renilla luciferase in a cap-dependent manner, whereas the firefly luciferase is only translated when a functional IRES element is present. In addition, a hairpin sequence inserted upstream of the renilla luciferase sequence served to minimize cap-dependent translation and read-through across the renilla termination codon (Fig. $6 \mathrm{~A})$. To determine the presence of an IRES within the $5^{\prime}$ UTR of egr2, egr2-5'UTR was inserted into the intercistronic region of phpRF, resulting in phpR-egr2-F. Cells transiently cotransfected with phpRF or phpR-egr2-F in combination with the $\beta$-galactosidase transfection control showed similar relative renilla activities (Fig. 6B). In contrast, the relative firefly activity was significantly higher in the presence of egr2-5'UTR (7.12 \pm 0.61-fold compared to $\mathrm{phpRF}$ ).

To gain final proof for the presence of an IRES within the egr2-5'UTR, we transfected in vitro transcribed mRNA of the bicistronic construct instead of DNA. While renilla luciferase signals remained at similar levels, firefly activity was again enhanced $12.3 \pm 0.83$-fold, when comparing hpR-egr2-F mRNA to hpRF mRNA (Fig. 6C). This observation served as uneqivocal proof for the presence of an IRES within the $5^{\prime}$ UTR of egr2. To rule out the contribution of cryptic promoter activity to the activity of the bicistronic constructs transfected as DNA, we introduced the egr2-5'UTR into the promoterless pGL3-basic vector. Insertion of egr2-5'UTR did not enhance firefly activity in transiently transfected MCF7 cells compared to the pGL3basic parent vector. In contrast, the positive control containing an SV40 promoter showed a strong relative luciferase activity compared to the promoterless vector (Fig. 6D). Thus, cryptic promoter activity was excluded. To assess if cryptic splicing might occur, we checked whether the bicistronic plasmid generates an mRNA transcript of the expected size. Specifically, the full-length transcript of the phpR-egr2-F (R-egr2-F) was predicted to contain $2933 \mathrm{nt}$, whereas the phpRF control vector should produce a transcript (RF) of $2587 \mathrm{nt}$. For this purpose, we treated mRNA isolated from cells transfected with either phpRF or phpRegr2-F with DNase to remove residual contaminations of the plasmid DNA. PCR with primers that specifically bind to the $5^{\prime}$ end of renilla and $3^{\prime}$ end of firefly open reading frames 
A

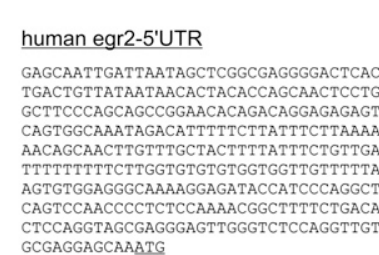

B

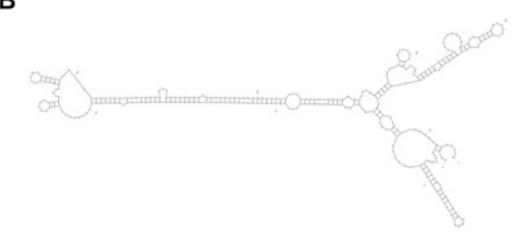

C

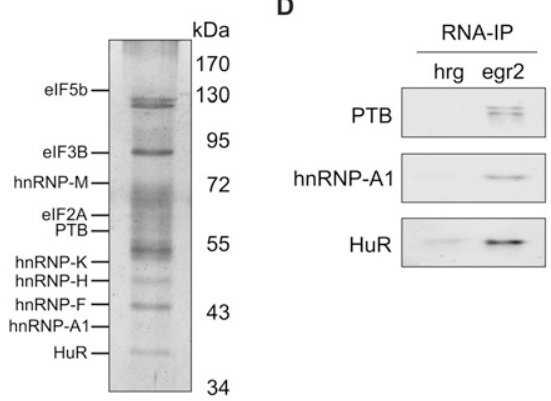

E

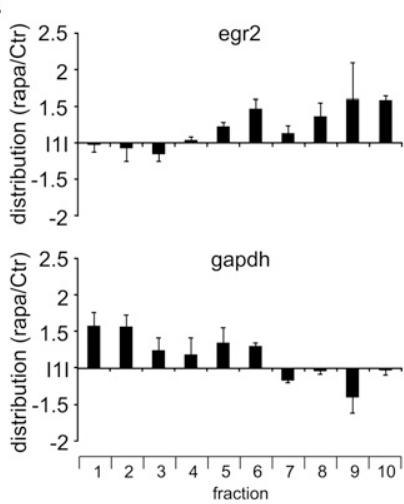

FIGURE 5. PTB binds to egr $2-5^{\prime}$ UTR. (A) Sequence of human egr $2-5^{\prime}$ UTR. (B) Predicted structure of the human egr2-5'UTR using mfold. (C) Lysates of CM-treated MCF7 cells were incubated with in vitro transcribed, biotinylated egr2-5'UTR. After immunoprecipitation using streptavidin agarose beads, bound proteins were separated on SDS-PAGE and visualized using silver staining. Individual proteins were identified by mass spectrometric analysis of gel slices. Positions of identified proteins are shown on the left side, protein molecular weight markers are shown on the right side. $(D)$ Lysates of CM-treated MCF7 cells were incubated with in vitro transcribed, biotinylated egr2-5'UTR or human reverse gapdh (hrg) RNA, before immunoprecipitation of proteins using streptavidin agarose beads. Bound proteins were subjected to Western analysis and probed with the indicated antibodies. Blots are representative for at least three independent experiments. (E) MCF7 cells were treated with rapamycin $(100 \mathrm{nM})$ for $4 \mathrm{~h}$ and subjected to polysomal fractionation. RNA from single fractions was isolated and egr2 and gapdh mRNA distribution changes were analyzed using RT-qPCR. Data are presented as means $\pm \operatorname{SEM}(n=3)$.

to amplify the full-length RL or R-egr2-L mRNAs resulted in a single product of the expected size for each vector (Fig. $6 \mathrm{E})$. While this observation verifies the generation of the full bicistronic mRNA, it does not rule out the presence of additional monocistronic firefly mRNAs. Therefore, we determined the expression of both renilla and firefly mRNAs in cells transfected with either phpRF control or phpR-egr2-F vectors. The ratio of firefly to renilla mRNA was not altered upon insertion of the egr2-5'UTR compared to the empty vector control (Fig. 6F); thus, cryptic splicing and cryptic promoter activity were excluded.

Taken together, these experiments indicate that cryptic promoter and splice sites do not account for the observed egr2-5'UTR-dependent increase in the bicistronic firefly signal. Furthermore, they strongly support the presence of an IRES element in the $5^{\prime}$ UTR of egr 2.

We next determined if the IRES activity, defined as the ratio of firefly to renilla luciferase activities, responds to CM. As predicted, IRES activity of phpR-egr2-F transfected cells was significantly induced in response to $24 \mathrm{~h} \mathrm{CM}(2.30 \pm$ 0.22-fold compared to Ctr) (Fig. 6G).

In the last set of experiments, we aimed at determining if the CM-induced IRES activity was also dependent on IL-1 $\beta$ and p38-MAPK activation. To this end, cells were transfected with phpR-egr2-F. Treatment with CM for $4 \mathrm{~h}$ led to a significant $1.5 \pm 0.18$-fold increase in egr2-IRES activity. Similarly, treatment with recombinant IL-1 $\beta$ alone resulted in a significant $1.34 \pm 0.11$-fold egr2IRES activation compared to Ctr cells (Fig. 7A). Importantly, CM-induced egr2IRES activity was significantly reduced by the p38-MAPK inhibitor SB203580 to $82 \pm 4 \%$ (Fig. $7 \mathrm{~B}$ ).

Thus, we conclude that within an inflammatory environment, IL-1 $\beta$ and p38-MAPK contribute to egr2-IRES-dependent translation.

\section{DISCUSSION}

In this report, we identify egr2 as a novel translationally regulated target. Specifically, we show that egr 2 mRNA shifts from monosomal to polysomal fractions upon treatment with supernatants of activated monocyte-derived macrophages that were previously shown to induce a proinflammatory as well as a protumorigenic program in MCF7 cells (Schmid et al. 2011). Enhanced egr2 translation resulted from IL-1 $\beta$ dependent p38-MAPK-mediated activation of a newly identified IRES within the 5' UTR of egr2.

So far, regulation of egr2 is only poorly understood. Some studies suggested transcriptional activation for egr2 (Yokota et al. 2010; Fang et al. 2011). A recent report identified miR-17-92 as binding to the $3^{\prime}$ UTR of egr2, reducing egr2 levels either by mRNA destabilization or suppression of translation in murine macrophages during leukemogenesis (Pospisil et al. 2011). In our hands, inflammatory conditions did not affect translation of egr 2 via its $3^{\prime}$ UTR as introducing the $3^{\prime}$ UTR into a reporter vector left luciferase activities upon treatment with CM unaltered (data not shown). Importantly, transfection of in vitro transcribed mRNA of the bicistronic vectors validated the presence of an IRES within the $5^{\prime}$ UTR of egr2 (Fig. 6C). In addition, the contribution of cryptic promoters, splicing, or read-through was excluded (Fig. 6). Furthermore, we found that IL-1 $\beta$ within the CM (Fig. 3A) contributed to enhanced IRES-dependent translation of egr2 via p38-MAPK activation (Fig. 7A,B). While IL-1 $\beta$ was previously shown to suppress translation of thrombomodulin (Yeh et al. 2008), 
A

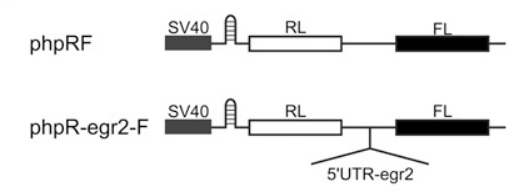

D

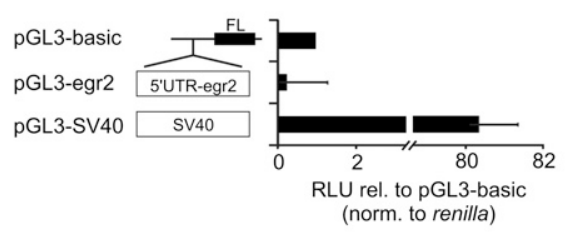

B

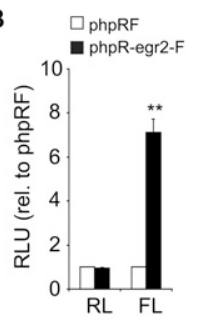

E

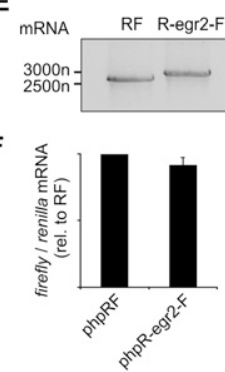

FIGURE 6. Egr2 contains an IRES element. (A) Scheme of bicistronic constructs used for reporter assays. (B) Bicistronic reporter plasmids were cotransfected with SV40- $\beta$-Gal plasmid into MCF7 cells. Twenty-four hours after transfection, renilla and firefly activities were measured and normalized to $\beta$-galactosidase activity. Data are presented as means \pm SEM $(n>$ 3). $\left(^{\star *}\right) P<0.01$ relative to phpRF. $(C)$ In vitro transcribed mRNAs of the indicated reporter plasmids were transfected into MCF7 cells. Twenty-four hours after transfection, renilla and firefly activities were measured. Data are presented as means \pm SEM $\left.(n>3) .{ }^{* *}\right) P<0.01$ relative to hpRF. (D) MCF7 cells were cotransfected with the indicated reporter constructs and SV40-renilla plasmid. Forty-eight hours after transfection, firefly activity was measured and normalized to renilla activity. Data are presented as means \pm SEM $(n>3)$. (E) RNA isolated from cells transfected with phpRF or phpR-egr2-F was DNAse-treated. cDNA was synthesized, and PCR was performed with specific primers to amplify full-length RL or R-egr2-L mRNAs. PCR products were visualized via agarose gel electrophoresis. Data are representative for at least three independent experiments. $(F)$ RT-qPCR analysis of the amount of firefly mRNA normalized to renilla mRNA. Data are presented as means \pm SEM $(n=3)$. (G) MCF7 cells were transfected with phpR-egr2-F and treated with CM or Ctr for $24 \mathrm{~h}$. IRES activity was calculated as the ratio of firefly to renilla activities and is given relative to Ctr. Data are presented as means \pm SEM $(n>3) .\left({ }^{*}\right) P<0.01$.

no translation-inducing function of IL- $1 \beta$ has been identified so far. Recently IL- $1 \alpha$ was reported to activate translation of mRNAs such as IкB $\zeta$ and IL-6 (Dhamija et al. 2010). Moreover, IL-6 was shown to enhance IRESdependent translation of prosurvival genes like c-myc (Shi et al. 2011). Notably, in our experiments, depletion of IL-1 $\beta$ did not fully repress CM-induced egr2 translation, and treatment with recombinant IL- $1 \beta$ did not completely recapitulate enhanced egr2 translation as seen in response to CM (Fig. 3B,C). Thus, besides IL-1 $\beta$, additional factors within the $\mathrm{CM}$, which remain to be elucidated, contribute to enhanced egr2 translation. Furthermore, our data corroborate previous reports showing that p38-MAPK activity is important for IRES-dependent translation of cyclin D1 and c-myc (Shi et al. 2005; Cloninger et al. 2011).

Further evidence for the presence of IRES elements within the $5^{\prime}$ UTR of egr 2 comes from our finding that various proteins that were previously described to function as ITAFs for other mRNAs bind to this region (Fig. 5C). Especially, PTB is considered to activate IRESs of many IRES-bearing mRNAs (Sawicka et al. 2008; Yang et al. 2010). Interestingly,

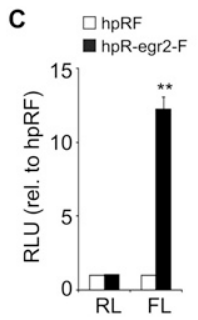

G

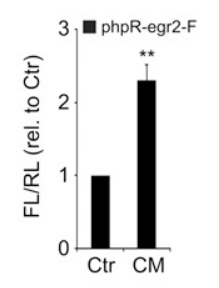

among a number of hnRNPs, we also found hnRNP-A1, which was previously shown to be crucial for the IRES function of c-myc (Shi et al. 2008) and fgf2 (Bonnal et al. 2005). While no differential binding of PTB and hnRNP-A1 was seen between CM- and Ctr-treated conditions, various other RNA-interacting proteins were found to bind to egr2-5'UTR as well. Interestingly, Papadopoulou et al. (2010) recently described a complex comprising a number of hnRNPs to interact with mRNAs. Changes in egr2-5'UTR binding complexes might, therefore, account for the translational regulation of egr2. As a detailed analysis of RNA-binding protein complexes and their subcellular localization is beyond the scope of the present study, future studies are required to identify those proteins that are critical for the regulation of IRES-dependent egr 2 translation. It can be speculated that either differential binding or recruitment of other factors is required to mediate the IREStransactivating function under inflammatory conditions.

Functionally, egr2 was described as a transcription factor belonging to the early growth response gene family that is activated immediately after serum addition (Joseph et al. 1988). It was shown to be crucial for hindbrain development (Nagarajan et al. 2001) and recently proposed to exert E3 SUMO ligase activity (GarciaGutierrez et al. 2011). Furthermore, egr2 was identified as an important regulator of T-cell tolerance by inhibiting IL-2 production, promoting a T-cell receptor-induced negative regulatory program. Egr2 was, therefore, proposed to be a good target in cancer therapy to evade tumor-induced immune tolerance (Safford et al. 2005). Its role in the regulation of cell proliferation is controversial, i.e., while egr2 was shown to be induced in cells overexpressing tumor suppressor PTEN (Matsushima-Nishiu et al. 2001), it also appears to induce the prosurvival protein Mcll and to stimulate proteasomal degradation of the proapoptotic protein Bim (Bradley et al. 2008). Thus, while egr2 translation is enhanced under conditions which we have previously shown to be protumorigenic (Yasuda et al. 2010; Schmid et al. 2011), the function of egr2 in this setting remains to be elucidated.

Taken together, we provide evidence for a novel mechanism of egr 2 regulation via enhanced IRES-dependent translation under proinflammatory conditions. This effect is mediated by IL- $1 \beta$ and other factors and involves 
A

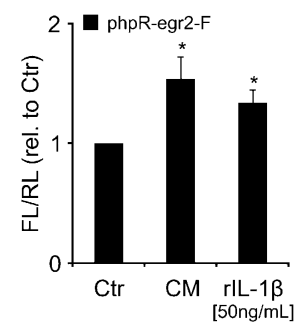

B

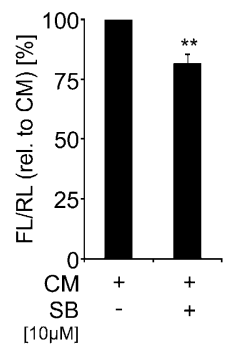

FIGURE 7. Egr2-IRES activity is p38-MAPK- and IL-1 $\beta$-dependent. (A) MCF7 cells were transfected with phpR-egr2-F. Forty-eight hours after transfection, cells were treated with Ctr, CM, or rIL-1 $\beta$ $(50 \mathrm{ng} / \mathrm{mL})$ for $4 \mathrm{~h}$. IRES activity was calculated as described before and is given relative to Ctr. Data are presented as means \pm SEM $(n>3) .\left(^{*}\right) P<0.05$. (B) MCF7 cells were transfected with phpR-egr2-F. Forty-eight hours after transfection, cells were treated for $4 \mathrm{~h}$ with $\mathrm{CM}$ or $\mathrm{CM}$ containing SB203580 $(10 \mu \mathrm{M})$. IRES activity was calculated as described before and is given relative to $\mathrm{CM}$. Data are presented as means $\pm \operatorname{SEM}(n>3)$. (**) $P<0.01$.

p38-MAPK activation. As egr2 plays a crucial rule in T-cell tolerance, an in-depth understanding of the regulation of egr2 will be of interest for conditions where T-cell activation should be therapeutically altered, such as transplantations or tumor immunotherapies.

\section{MATERIALS AND METHODS}

\section{Materials}

All chemicals were purchased from Sigma-Aldrich, if not indicated otherwise. Antibodies were obtained from the following sources: anti-phospho-p38 (Thr180/Tyr182), anti-p38, and antihnRNP-A1 from Cell Signaling Technology, anti-nucleolin and anti-HuR from Santa Cruz Biotechnology, anti-IL-1 $\beta$ and IgG isotype from R\&D System $\mathrm{GmbH}$, and IRDyes 680LT and 800CW secondary antibodies from Li-COR Biosciences GmbH. Anti-PTB was a kind gift of Prof. Anne Willis (Spriggs et al. 2009). Recombinant IL-1 $\beta$ came from Peprotech. Rapamycin was purchased from Cell Signaling Technology and SB203580 from Enzo Life Science.

\section{Cell culture}

Cell lines came from LGC Standards GmbH. MCF7 and U937 cells were maintained in RPMI medium supplemented with $10 \%$ fetal bovine serum (FBS), $100 \mathrm{U} / \mathrm{mL}$ penicillin, $100 \mu \mathrm{g} / \mathrm{mL}$ streptomycin, and $2 \mathrm{mM}$ L-glutamine. Additionally, U937 media contained $1 \mathrm{mM}$ sodium pyruvate. Cells were kept at $37^{\circ} \mathrm{C}$ in a humidified atmosphere with $5 \% \quad \mathrm{CO}_{2}$. Medium and supplements were purchased from PAA. FBS came from Biochrom.

\section{Macrophage differentiation and conditioned medium}

U937 monocytes $\left(1 \times 10^{7} / 25 \mathrm{~mL}\right)$ were exposed to TPA $(10 \mathrm{nM})$ for $48 \mathrm{~h}$. The resulting adherent, activated U937 monocytederived macrophages were trypsinized, pelleted, and washed with PBS. For control purposes, undifferentiated U937 monocytes $(3 \times$ $\left.10^{6} / 25 \mathrm{~mL}\right)$ were incubated with DMSO $(0.1 \%)$ for $48 \mathrm{~h}$, pelleted by centrifugation, and washed with PBS. Subsequently, control and differentiated U937 were treated equally. For the generation of conditioned medium, U937 cells were reseeded at a concentration of $2 \times 10^{6} / 5 \mathrm{~mL}$. Cells were allowed to condition medium for $24 \mathrm{~h}$ followed by centrifugation, sterile filtration $(0.45 \mu \mathrm{m}$ filter $)$, and storage at $-80^{\circ} \mathrm{C}$ until further use. All experiments were carried out in U937 medium. To determine the secretion of IL-1 $\beta$ by the U937 cells, conditioned media were analyzed using the BD Cytometric Bead Array (CBA) Human Inflammation Kit according to the manufacturer's manual. Samples were measured using the BD LSRFortessa flow cytometer and analyzed with the BD Biosciences FCAP software (BD Biosciences).

\section{Polysomal fractionation}

$7.5 \times 10^{6}$ MCF7 cells were seeded in a $15-\mathrm{cm}$ dish $1 \mathrm{~d}$ prior to treatment of the cells, followed by polysomal fractionation. Briefly, after incubation with $100 \mu \mathrm{g} / \mathrm{mL}$ cycloheximide (CHX) for $10 \mathrm{~min}$ at $37^{\circ} \mathrm{C}$, cells were harvested in PBS/CHX $(100 \mu \mathrm{g} / \mathrm{mL})$ and lysed in $750 \mu \mathrm{L}$ polysome buffer $(140 \mathrm{mM} \mathrm{KCl}, 20 \mathrm{mM}$ Tris$\mathrm{HCl}[\mathrm{pH} 8.0], 5 \mathrm{mM} \mathrm{MgCl} 2,0.5 \% \mathrm{NP} 40,0.5 \mathrm{mg} / \mathrm{mL}$ heparin, $1 \mathrm{mM}$ DTT, $100 \mathrm{U} / \mathrm{mL}$ RNasin [Promega], $100 \mu \mathrm{g} / \mathrm{mL}$ CHX). After pelleting, the cytoplasmic lysates were layered onto $11-\mathrm{mL} 10 \%-$ $50 \%$ continuous sucrose gradients. The gradients were centrifuged at $35,000 \mathrm{rpm}$ for $2 \mathrm{~h}$ at $4^{\circ} \mathrm{C}$ without brake using a SW40 rotor in a Beckman ultracentrifuge. Afterward, the gradients were collected in 1-mL fractions using a Biologic LP system (Biorad). Absorbance was measured at $254 \mathrm{~nm}$. RNA was precipitated by $1 / 10$ volume sodium acetate $(3 \mathrm{M})$ and 1 volume isopropanol. RNA was further purified using the RNeasy MiniKit (Qiagen) according to the manufacturer's manual. For quality control, equal volumes of RNA of each fraction were analyzed by denaturing agarose gel electrophoresis. RNA was transcribed using the Maxima First Strand cDNA synthesis kit from Fermentas, and subsequently, individual mRNAs were analyzed using real-time PCR with Absolute qPCR SYBR Green Fluorescent mix (Thermo Fisher Scientific). Results are shown as the percentage of mRNA in the single fractions relative to the total amount of mRNA extracted from all fractions. Specific primers were individually designed (gapdhfwd: TGCACCACCAACTGCTTAGC, gapdh-rev: GGCATGGAC TGTGGTCATGAG; egr2-fwd: ACGTCGGTGACCATCTTTCCCA AT, egr2-rev: TGCCCATGTAAGTGAAGGTCTGGT; egr3-fwd: GC TTTGTTCAGTTCGGATCGCCTT, egr3-rev: AAACAATGAGGTG TTTGGG TCGGG; firefly-fwd: ATTTATCGGAGTTGCAGTTGCG CC, firefly-rev: GCTGCGAAATG CCCATACTGTTGA; renilla-fwd: CAGTGGTGGGCCAGATGTAAACAA, renilla-rev: TAAGAAGAGG CCGCGTTACCATGT). 


\section{Microarray analysis}

For analysis of the polysomal RNA samples, fractions 6-10 from the gradients were pooled. Additionally, total RNA was collected. RNA concentrations were determined using the NanoDrop spectrophotometer (NanoDrop Technologies). RNA quality was assessed using a 2100 Bioanalyzer (Agilent Technologies). RNA was labeled, quality controlled, and hybridized to Illumina HumanHT-12_V3 BeadChip arrays (Illumina, Inc.) at the DKFZ Genomics and Proteomics Core Facility. Data extraction was done for all beads individually, and outliers were removed when MAD (median absolute deviation) $>2.5$. All remaining data points were used for the calculation of the mean average signal for a given probe, and standard deviation for each probe was calculated. The statistical analysis was done with the statistical computing environment R version 2.12 (R Development Core Team 2005). Additional software packages were taken from the Bioconductor project (Gentleman et al. 2004).

\section{Western analysis}

For Western analysis, cells were lysed and snap-frozen in lysis buffer (50 mM Tris- $\mathrm{HCl}, 0.27 \mathrm{M}$ sucrose, $1 \mathrm{mM}$ Na-ortho-vanadate, $1 \mathrm{mM}$ EDTA, $1 \mathrm{mM}$ EGTA, $10 \mathrm{mM}$ Na- $\beta$-glyercolphosphate, $50 \mathrm{mM}$ $\mathrm{NaF}, 5 \mathrm{mM}$ Na-pyrophosphate, $1 \%$ Triton-X-100, and protease inhibitor mix [Roche]). Fifty $\mu \mathrm{g}$ of protein were separated on SDSpolyacrylamide gels and transferred onto nitrocellulose membranes. Proteins were detected using specific antibodies and appropriate secondary antibodies and visualized on an Odyssey infrared imaging system (Li-COR Biosciences $\mathrm{GmbH}$ ).

\section{RNA affinity chromatography}

Egr2-5'UTR (based on NM_000399.3) and partial human reverse gapdh were transcribed in vitro with the MEGAShortscript Transcription kit (Ambion) according to the manufacturer's protocol. The transcript was biotinylated at the $5^{\prime}$ end with the $5^{\prime}$ EndTag Nucleic Acid Labeling System (Enzo Life Science) according to the manufacturer's instructions. Twenty $\mu \mathrm{g}$ of biotinylated RNA was conjugated to streptavidin agarose beads in incubation buffer (10 mM Tris- $\mathrm{HCl}$ [pH 7.4], $150 \mathrm{mM} \mathrm{KCl,} 0.5 \mathrm{mM} \mathrm{DTT,} 0.05 \%$ $\mathrm{NP} 40,100 \mathrm{U} / \mathrm{mL}$ RNasin) at $4^{\circ} \mathrm{C}$ for $2 \mathrm{~h}$ with continuous rotation. Five hundred $\mu \mathrm{g}$ of cytoplasmic proteins of MCF7 cells that were lysed in incubation buffer containing $0.5 \%$ NP40 were added to the beads and incubated for $1 \mathrm{~h}$ at $4^{\circ} \mathrm{C}$ followed by $15 \mathrm{~min}$ at room temperature. Beads were washed five times with incubation buffer, resuspended in $30 \mu \mathrm{L} 4 \times$ Laemmli buffer and boiled for $10 \mathrm{~min}$. Eluted proteins were separated by $10 \%$ SDS-PAGE and visualized using silver staining. For MS analysis, SDS gels were stained with Coomassie blue. Corresponding gel lanes were cut in several slices, and proteins were tryptically in-gel digested. Resulting peptides were analyzed by nano-ESI-LC-MS/MS using an LTQ-Orbitrap XL mass spectrometer and an Agilent 1200 nano-HPLC system at the front end. Obtained mass spectra were searched against the speciesspecific Uniprot protein database (Homo sapiens) using the Mascot 2.2 search engine. Peptide matches were filtered by Mascot score cut-off with significance threshold at $P<0.05$.

\section{Plasmid construction}

Primers were designed to amplify the human egr2-5'UTR using RNA extracted from human MCF7 cells (fwd: GGCCGAATTC
GAGCAATTGATAAAGCTCG, rev: TTAACCATGGTT GCTCCT CGCACAAC). A single product of $326 \mathrm{nt}$ was obtained and inserted into the hairpin-containing bicistronic vector phpRF (kind gift of Prof. Anne Willis) (Coldwell et al. 2000) with SpeI and NcoI, resulting in phpR-egr2-F. Human egr2-5'UTR was also cloned into the promoter-less pGL3-basic vector using HindIII and NcoI, resulting in pGL3-egr2. To rule out cryptic splicing events mediated by the $5^{\prime}$ UTR of egr2 in the bicistronic vectors, primers were designed to bind to the $5^{\prime}$ end of the renilla ORF and the $3^{\prime}$ end of the firefly ORF (fwd: ATGACTTCGAAAGTTTATGATCCAGAACAAA GGAAACGG, rev: TTACACGGCGATCTTTCCGCCCT). For in vitro transcription, egr2-5'UTR was cloned into the pcDNA3.1 $(+)$ vector downstream from the T7-promoter using HindIII and XhoI as described before and linearized with XhoI. pDrive-hr-gapdh was a kind gift of Andreas von Knethen and linearized with NotI.

\section{Reporter assays}

MCF7 cells were transiently transfected with the $0.2 \mu \mathrm{g}$ DNA using Rotifect reagent (Roth) according to the manufacturer's protocol. After $16 \mathrm{~h}$, the medium was changed, and cells were stimulated. Following stimulation, cells were lysed, and firefly and renilla luciferase activities were determined using a Dual Luciferase kit assay (Promega) on a Mithras LB 940 luminometer (Berthold). As a transfection control, the SV40- $\beta$-Gal vector (Promega) was cotransfected, and $\beta$-galactosidase activity was determined using the $\beta$-Galactosidase Enzyme Assay System (Promega).

For RNA transfection DNA constructs were linearized with BamHI and in vitro transcribed using the mMESSAGE mMACHINE T7 Kit (Ambion) according to the manufacturer's protocol and purified with the MEGAclear Kit (Ambion). Twotenths $\mu \mathrm{g}$ of RNA were transfected as described for DNA. Luciferase activities were measured $24 \mathrm{~h}$ post-transfection.

\section{Statistical analysis}

Each experiment was performed at least three times. Data are presented as mean values \pm SEM. Statistical analysis was performed using Student's $t$-test.

\section{DATA DEPOSITION}

The complete gene expression data set has been deposited in the Gene Expression Omnibus under accession no. GSE35022.

\section{SUPPLEMENTAL MATERIAL}

Supplemental material is available for this article.

\section{ACKNOWLEDGMENTS}

We thank Prof. Georg Auburger, Prof. Ulrich Brandt, and Dr. Christopher Tiedje for providing technical support and Mirco Steger for assisting with in-gel digestion and mass spectrometry analysis. This work was supported by LOEWE-Schwerpunkt OSF (III L 4-518/55.004 [2009]) funded by the Hessian Ministry of Higher Education, Research and Arts and the DFG (BR999 and SFB815).

Received February 28, 2012; accepted July 17, 2012. 


\section{REFERENCES}

Averous J, Fonseca BD, Proud CG. 2008. Regulation of cyclin D1 expression by mTORC1 signaling requires eukaryotic initiation factor 4E-binding protein 1. Oncogene 27: 1106-1113.

Bonnal S, Pileur F, Orsini C, Parker F, Pujol F, Prats AC, Vagner S. 2005. Heterogeneous nuclear ribonucleoprotein Al is a novel internal ribosome entry site trans-acting factor that modulates alternative initiation of translation of the fibroblast growth factor 2 mRNA. J Biol Chem 280: 4144-4153.

Bradley EW, Ruan MM, Oursler MJ. 2008. Novel pro-survival functions of the Kruppel-like transcription factor Egr2 in promotion of macrophage colony-stimulating factor-mediated osteoclast survival downstream of the MEK/ERK pathway. J Biol Chem 283: 8055-8064.

Cloninger C, Bernath A, Bashir T, Holmes B, Artinian N, Ruegg T, Anderson L, Masri J, Lichtenstein A, Gera J. 2011. Inhibition of SAPK2/p38 enhances sensitivity to mTORC1 inhibition by blocking IRES-mediated translation initiation in glioblastoma. Mol Cancer Ther 10: 2244-2256.

Cobbold LC, Wilson LA, Sawicka K, King HA, Kondrashov AV, Spriggs KA, Bushell M, Willis AE. 2010. Upregulated c-myc expression in multiple myeloma by internal ribosome entry results from increased interactions with and expression of PTB-1 and YB-1. Oncogene 29: 2884-2891.

Coldwell MJ, Mitchell SA, Stoneley M, MacFarlane M, Willis AE. 2000. Initiation of Apaf-1 translation by internal ribosome entry. Oncogene 19: 899-905.

Dhamija S, Doerrie A, Winzen R, Dittrich-Breiholz O, Taghipour A, Kuehne N, Kracht M, Holtmann H. 2010. IL-1-induced posttranscriptional mechanisms target overlapping translational silencing and destabilizing elements in IкBל mRNA. J Biol Chem 285: 29165-29178.

Faivre S, Kroemer G, Raymond E. 2006. Current development of mTOR inhibitors as anticancer agents. Nat Rev Drug Discov 5: 671-688.

Fang F, Ooka K, Bhattacharyya S, Wei J, Wu M, Du P, Lin S, Del Galdo F, Feghali-Bostwick CA, Varga J. 2011. The early growth response gene Egr2 (alias Krox20) is a novel transcriptional target of transforming growth factor- $\beta$ that is up-regulated in systemic sclerosis and mediates profibrotic responses. Am J Pathol 178: 2077-2090.

Garcia-Gutierrez P, Juarez-Vicente F, Gallardo-Chamizo F, Charnay P, Garcia-Dominguez M. 2011. The transcription factor Krox20 is an E3 ligase that sumoylates its Nab coregulators. EMBO Rep 12: 1018-1023.

Gentleman RC, Carey VJ, Bates DM, Bolstad B, Dettling M, Dudoit S, Ellis B, Gautier L, Ge Y, Gentry J, et al. 2004. Bioconductor: Open software development for computational biology and bioinformatics. Genome Biol 5: R80. doi: 10.1186/gb-2004-5-10-r80.

Guertin DA, Sabatini DM. 2007. Defining the role of mTOR in cancer. Cancer Cell 12: 9-22.

Holcik M. 2004. Targeting translation for treatment of cancer-a novel role for IRES? Curr Cancer Drug Targets 4: 299-311.

Ichijo H. 1999. From receptors to stress-activated MAP kinases. Oncogene 18: 6087-6093.

Joseph LJ, Le Beau MM, Jamieson GA Jr, Acharya S, Shows TB, Rowley JD, Sukhatme VP. 1988. Molecular cloning, sequencing, and mapping of EGR2, a human early growth response gene encoding a protein with "zinc-binding finger" structure. Proc Natl Acad Sci 85: 7164-7168.

Lang KJ, Kappel A, Goodall GJ. 2002. Hypoxia-inducible factor- $1 \alpha$ mRNA contains an internal ribosome entry site that allows efficient translation during normoxia and hypoxia. Mol Biol Cell 13: $1792-1801$.

Matsushima-Nishiu M, Unoki M, Ono K, Tsunoda T, Minaguchi T, Kuramoto H, Nishida M, Satoh T, Tanaka T, Nakamura Y. 2001. Growth and gene expression profile analyses of endometrial cancer cells expressing exogenous PTEN. Cancer Res 61: 3741-3749.
Nagarajan R, Svaren J, Le N, Araki T, Watson M, Milbrandt J. 2001. EGR2 mutations in inherited neuropathies dominant-negatively inhibit myelin gene expression. Neuron 30: 355-368.

Papadopoulou C, Patrinou-Georgoula M, Guialis A. 2010. Extensive association of $\mathrm{HuR}$ with hnRNP proteins within immunoselected hnRNP and mRNP complexes. Biochim Biophys Acta 1804: 692703.

Pause A, Belsham GJ, Gingras AC, Donze O, Lin TA, Lawrence JC Jr, Sonenberg N. 1994. Insulin-dependent stimulation of protein synthesis by phosphorylation of a regulator of $5^{\prime}$-cap function. Nature 371: 762-767.

Pickering BM, Willis AE. 2005. The implications of structured $5^{\prime}$ untranslated regions on translation and disease. Semin Cell Dev Biol 16: 39-47.

Pospisil V, Vargova K, Kokavec J, Rybarova J, Savvulidi F, Jonasova A, Necas E, Zavadil J, Laslo P, Stopka T. 2011. Epigenetic silencing of the oncogenic miR-17-92 cluster during PU.1-directed macrophage differentiation. EMBO J 30: 4450-4464.

Proud CG. 2004. Role of mTOR signalling in the control of translation initiation and elongation by nutrients. Curr Top Microbiol Immunol 279: 215-244.

Proud CG. 2006. Regulation of protein synthesis by insulin. Biochem Soc Trans 34: 213-216.

R Development Core Team. 2005. R: A language and environment for statistical computing. R Foundation for Statistical Computing, Vienna, Austria.

Safford M, Collins S, Lutz MA, Allen A, Huang CT, Kowalski J, Blackford A, Horton MR, Drake C, Schwartz RH, et al. 2005. Egr-2 and Egr-3 are negative regulators of T cell activation. Nat Immunol 6: $472-480$.

Sawicka K, Bushell M, Spriggs KA, Willis AE. 2008. Polypyrimidinetract-binding protein: A multifunctional RNA-binding protein. Biochem Soc Trans 36: 641-647.

Schmid T, Bajer MM, Blees JS, Eifler LK, Milke L, Rübsamen D, Schulz K, Weigert A, Baker AR, Colburn NH, et al. 2011. Inflammation-induced loss of Pdcd4 is mediated by phosphorylation-dependent degradation. Carcinogenesis 32: 1427-1433.

Sherrill KW, Byrd MP, Van Eden ME, Lloyd RE. 2004. BCL-2 translation is mediated via internal ribosome entry during cell stress. J Biol Chem 279: 29066-29074.

Shi Y, Sharma A, Wu H, Lichtenstein A, Gera J. 2005. Cyclin D1 and c-myc internal ribosome entry site (IRES)-dependent translation is regulated by AKT activity and enhanced by rapamycin through a p38 MAPK- and ERK-dependent pathway. J Biol Chem 280: 10964-10973.

Shi Y, Frost PJ, Hoang BQ, Benavides A, Sharma S, Gera JF, Lichtenstein AK. 2008. IL-6-induced stimulation of c-myc translation in multiple myeloma cells is mediated by myc internal ribosome entry site function and the RNA-binding protein, hnRNP A1. Cancer Res 68: 10215-10222.

Shi Y, Frost P, Hoang B, Benavides A, Gera J, Lichtenstein A. 2011. IL-6-induced enhancement of c-Myc translation in multiple myeloma cells: Critical role of cytoplasmic localization of the rna-binding protein hnRNP Al. J Biol Chem 286: 67-78.

Silvera D, Formenti SC, Schneider RJ. 2010. Translational control in cancer. Nat Rev Cancer 10: 254-266.

Sonenberg N, Hinnebusch AG. 2007. New modes of translational control in development, behavior, and disease. Mol Cell 28: 721-729.

Sonenberg N, Hinnebusch AG. 2009. Regulation of translation initiation in eukaryotes: Mechanisms and biological targets. Cell 136: 731-745.

Spriggs KA, Bushell M, Mitchell SA, Willis AE. 2005. Internal ribosome entry segment-mediated translation during apoptosis: The role of IRES-trans-acting factors. Cell Death Differ 12: 585591.

Spriggs KA, Cobbold LC, Ridley SH, Coldwell M, Bottley A, Bushell M, Willis AE, Siddle K. 2009. The human insulin receptor mRNA contains a functional internal ribosome entry segment. Nucleic Acids Res 37: 5881-5893. 


\section{Rübsamen et al.}

Vagner S, Galy B, Pyronnet S. 2001. Irresistible IRES. Attracting the translation machinery to internal ribosome entry sites. EMBO Rep 2: 893-898.

Wek RC, Jiang HY, Anthony TG. 2006. Coping with stress: eIF2 kinases and translational control. Biochem Soc Trans 34: 7-11.

Yang L, Gu L, Li Z, Zhou M. 2010. Translation of TRAF1 is regulated by IRES-dependent mechanism and stimulated by vincristine. Nucleic Acids Res 38: 4503-4513.

Yasuda M, Schmid T, Rübsamen D, Colburn NH, Irie K, Murakami A. 2010. Downregulation of programmed cell death 4 by inflammatory conditions contributes to the generation of the tumor promoting microenvironment. Mol Carcinog 49: 837-848.
Yeh CH, Hung LY, Hsu C, Le SY, Lee PT, Liao WL, Lin YT, Chang WC, Tseng JT. 2008. RNA-binding protein HuR interacts with thrombomodulin 5'untranslated region and represses internal ribosome entry site-mediated translation under IL-1 $\beta$ treatment. Mol Biol Cell 19: 3812-3822.

Yokota I, Sasaki Y, Kashima L, Idogawa M, Tokino T. 2010. Identification and characterization of early growth response 2, a zinc-finger transcription factor, as a p53-regulated proapoptotic gene. Int J Oncol 37: 1407-1416.

Zuker M. 2003. Mfold web server for nucleic acid folding and hybridization prediction. Nucleic Acids Res 31: 34063415 . 

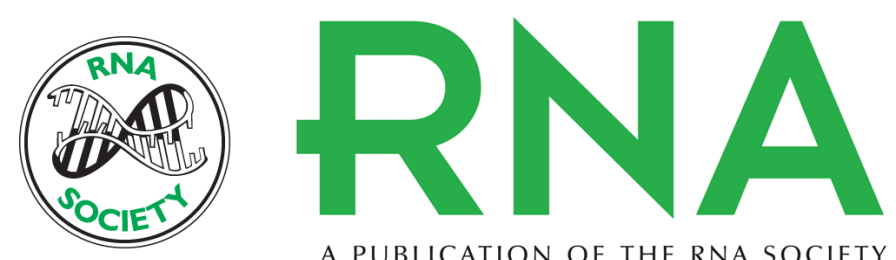

A PUBLICATION OF THE RNA SOCIETY

\section{IRES-dependent translation of egr2 is induced under inflammatory conditions}

Daniela Rübsamen, Johanna S. Blees, Kathrin Schulz, et al.

RNA 2012 18: 1910-1920 originally published online August 22, 2012

Access the most recent version at doi:10.1261/rna.033019.112

Supplemental http://rnajournal.cshlp.org/content/suppl/2012/08/07/rna.033019.112.DC1
Material

References This article cites 43 articles, 13 of which can be accessed free at:

http://rnajournal.cshlp.org/content/18/10/1910.full.html\#ref-list-1

\section{License}

Email Alerting Receive free email alerts when new articles cite this article - sign up in the box at the Service top right corner of the article or click here. 